\title{
Efecto de la fertilización nitrogenada sobre la producción y composición de Cynodon plectostachyus
}

\author{
Méndez, R. ${ }^{1}$; Fernández, J.A.'; Yáñez, E.A. ${ }^{2}$ \\ ${ }^{1}$ Actividad privada, Chaco, Argentina. ${ }^{2}$ Profesores Depto. Producción Animal, \\ Fac.Cs.Agrarias, Univ.Nac.del Nordeste, Cabral 2139, Corrientes 3400, Argentina. \\ E-mail: enriquey.mv@gmail.com
}

\begin{abstract}
Resumen
Méndez, R.; Fernández, J.A.; Yáñez, E.A.: Efecto de la fertilización nitrogenada sobre la producción y composición de Cynodon plectostachyus. Rev. Vet. 30: 1, 48-53, 2019. Con el objetivo de evaluar cómo afecta la aplicación de diferentes dosis de urea sobre la producción de materia seca (MS) y la composición nutricional del "pasto estrella", se realizó un ensayo aplicando tres niveles de fertilización nitrogenada: T0: testigo $(0 \mathrm{~kg} / \mathrm{N} / \mathrm{ha}), \mathrm{T} 1: 40,5 \mathrm{~kg} / \mathrm{N} /$ ha, y T2: $81 \mathrm{~kg} / \mathrm{N} / \mathrm{ha}$. La parcela donde se aplicaron los tratamientos presentaba una pastura de C. plectostachyus (Pilger), con 15 años de implantada y nunca fertilizada, utilizada para pastoreo directo con altas cargas. Se utilizó un diseño en bloques completos al azar, con tres tratamientos y tres repeticiones, aplicando el fertilizante al inicio del trabajo, luego de un corte de emparejamiento. Los cortes se realizaron en el mismo año, los días 23/04, 14/05 y 16/06. A partir de las muestras se obtuvo la producción de MS y en el laboratorio se efectuó la determinación de proteína bruta (PB) y fibra detergente neutro (FDN). La fertilización nitrogenada del "pasto estrella" produjo un aumento de la producción de MS, de hasta el $40 \%$ para todo el período analizado, siendo mayor a $25 \%$ en el primer corte. La concentración de PB aumentó aproximadamente un $20 \%$ con la aplicación de nitrógeno al inicio del otoño, manteniendo este efecto durante 2 meses, luego de lo cual desapareció. La respuesta fue mayor para T1. La concentración de FDN no fue afectada por la fertilización nitrogenada, aunque se observó menor FDN en el primer corte, para todos los tratamientos. La combinación de mayor concentración de PB y menor de FDN, implica una mejoría en la calidad nutricional de la pastura en el período inicial post-fertilización.
\end{abstract}

Palabras clave: pasto estrella, fertilización nitrogenada, calidad nutricional, rendimiento, proteína, urea.

\begin{abstract}
Méndez, R.; Fernández, J.A.; Yáñez, E.A.: Effects of nitrogen fertilization on the production and composition of Cynodon plectostachyus. Rev. Vet. 30: 1, 48-53, 2019. To evaluate how the application of different doses of urea affects the production of dry matter (DM) and nutritional composition of star grass, a trial applying three levels of nitrogen fertilization was conducted: T0: control (0 kg/N/ha), T1: $40.5 \mathrm{~kg}$ of N/ha, T2: $81 \mathrm{~kg}$ of N/ha. The plot where treatments were applied presents a pasture of C. plectostachyus, with 15 years of implantation and never fertilized, used for direct grazing with high loads. A complete random blocks design was used, with three treatments and three repetitions, applying the fertilizer at the beginning of the work, after a pairing cut. The cuts were made on 23/04, 14/05 and 16/06. From the samples obtained, the DM production was evaluated and at the laboratory, $\mathrm{DM}$, crude protein (CP) and neutral detergent fiber (NDF) were determined. The nitrogenous fertilization of "star grass" produced an increase in DM production of up to $40 \%$ for the whole period analyzed, being more than $25 \%$ in the first cut. The $\mathrm{CP}$ concentration increases approximately $20 \%$ with the application of nitrogen at the beginning of autumn, maintaining this effect for 2 months, after which it disappears. The answer was greater for T1. The concentration of NDF was not affected by nitrogen fertilization, although it is observed less NDF in the first cut, for all treatments. The combination of higher concentration of CP and lower NDF, implies an improvement in the nutritional quality of the pasture in the initial post-fertilization period.
\end{abstract}

Key words: star grass, nitrogen fertilization, nutritional quality, yield, protein, urea. 


\section{INTRODUCCIÓN}

El avance de la agricultura en Argentina viene desplazando a la ganadería hacia zonas consideradas marginales del norte del país, donde los pastizales naturales son la base de la cadena forrajera. Estas pasturas, megatérmicas y de crecimiento estival, son de baja calidad nutritiva. Su digestibilidad rara vez supera el $60 \%$ y presentan gran variación durante el año.

La concentración de proteína bruta (PB) también es menor comparada con las gramíneas templadas y con las subtropicales implantadas, alcanzando el $8-10 \%$ en brotes recientes y disminuyendo al $4-6 \%$ en plantas florecidas y/o durante el invierno. Estos valores de PB están en el límite o por debajo de los requerimientos nutritivos de los vacunos ${ }^{14}$.

Una de las herramientas para mejorar la producción de forraje, sería la implantación de nuevas especies de mayor productividad y mejores valores nutritivos, que se adapten a la zona y que puedan suplir la disminución de alimentos en la época invernal. En las pasturas tropicales, la última premisa se podría lograr a través de la henificación o del diferimiento de la producción para su pastoreo en invierno.

Una alternativa para estas zonas es el "pasto estrella" (Cynodon plectostachyus Pilger), planta nativa del continente africano (Kenya, Tanzania), muy empleada para pastoreo y henificación, así como para el control de la erosión de suelos. Además, es fácilmente adaptable a diferentes ambientes, con gran capacidad para soportar el manejo inadecuado y el sobre-pastoreo.

La introducción de esta planta en la Provincia del Chaco (Argentina) se realizó a través del Instituto Nacional de Tecnología Agropecuaria (INTA Colonia Benítez), con ejemplares oriundos de una provincia limítrofe (Corrientes). A su vez, es posible que la introducción del "pasto estrella" en esta última provincia, fuera realizada con material traído de Paraguay ${ }^{15}$.

C. plectostachyus es una gramínea perenne, con largos estolones de crecimiento rápido, que cubren abundantemente el suelo desnudo formando una densa red. La planta alcanza de 50 a $150 \mathrm{~cm}$ de altura. Las hojas son pilosas, planas, de hasta $20 \mathrm{~cm}$ de largo por 3-6 $\mathrm{mm}$ de ancho. La inflorescencia presenta de 6 a 12 espigas que rara vez sobrepasan los $8 \mathrm{~cm}$ de largo. Algunas variedades producen buenas cosechas de semillas en zonas de baja humedad, pero en general, la propagación se realiza por métodos vegetativos.

Esta planta es una gramínea de clima subtropical húmedo, de crecimiento estival, sensible a las heladas y resistente a la sequías, que se adapta fácilmente a una gran diversidad de ambientes. A mayor temperatura, mayor es la producción y a menor temperatura la producción disminuye, siendo la optima entre 25 y $38^{\circ} \mathrm{C}^{16}$.

La especie se destaca por su plasticidad con respecto a las condiciones ambientales. Si bien su buen desarrollo ocurre en ambientes cálidos, con un régimen de abundantes lluvias y sobre suelos de textura franco a franco-arenoso, sin condiciones de salinidad, los en- sayos de campo demuestran que se adapta rápidamente a condiciones de aridez y salinidad ${ }^{14}$.

Además se caracteriza por su capacidad de soportar errores de manejo, en particular el sobre-pastoreo con intenso pisoteo en condiciones de humedad, pues con un descanso adecuado se produce un excelente rebrote y recuperación de la cobertura del suelo. A esto se suma que ante el aumento de temperatura al inicio de la primavera, rápidamente ofrece forraje con abundantes hojas verdes.

En relación con la producción de carne, pueden lograrse ganancias de peso individual de hasta $640 \mathrm{~g} /$ animal/día y ganancias de peso anual de $1.538 \mathrm{~kg} / \mathrm{ha}$, siendo una pastura capaz de resistir altas cargas ${ }^{7}$.

Grandes incrementos en la producción de carne han sido logrados usando fertilizantes nitrogenados en pastos tropicales, independientemente de la especie. Frecuentemente los niveles de producción han sido superiores a los logrados en mezclas de gramíneas y leguminosas. En Australia distintos autores evaluaron la ganancia de peso vivo utilizando pasturas tropicales (Setaria sp y Gramma sp): aplicando entre 170 y $300 \mathrm{~kg}$ de nitrógeno, obtuvieron ganancias de peso vivo entre 500 y $820 \mathrm{~kg} / \mathrm{ha} / \mathrm{añon}^{9,10}$.

Esta investigación tuvo como objetivo evaluar el efecto de la fertilización nitrogenada sobre la producción de materia seca (MS) y la composición nutricional del "pasto estrella".

\section{MATERIAL Y MÉTODOS}

La experiencia a campo se realizó en un establecimiento cercano a la localidad de Colonia Elisa, Departamento Sargento Cabral (Chaco, Argentina). El campo cuenta con una superficie de 2.500 ha y realiza actividades agrícolas y de invernada, con suplementación en pastoreo y -en menor medida- en confinamiento.

El clima de la región corresponde a un ambiente subtropical húmedo con estación seca. El registro promedio de lluvia para la zona es de $1.200 \mathrm{~mm}$ anuales, concentrándose la mayor parte de las lluvias en primavera-verano. Los inviernos son secos y el mes más crítico es julio ${ }^{2}$, con una media de $30 \mathrm{~mm}$. De acuerdo a los registros del establecimiento, las precipitaciones en el periodo del ensayo fueron de $341 \mathrm{~mm}$, con casi 300 $\mathrm{mm}$ llovidos entre la fertilización y el primer corte.

Para el ensayo se dispuso de una superficie de 2 ha, sobre suelos de la serie Martina (natrustalf típico), que se encuentran en lomas cerradas y presentan un horizonte superficial lixiviado, color gris parduzcoclaro, con textura media. El subsuelo es gris oscuro, de textura pesada, con moderado contenido de materia orgánica, buena a alta capacidad de retención de agua, hasta $1,45 \mathrm{~m}$ de profundidad. Es fuertemente ácido hasta los $45 \mathrm{~cm}$ y luego neutro; muy rico en calcio, bueno en magnesio, rico en potasio, fuertemente sódico, con moderadamente alta capacidad de intercambio catiónico y porcentaje medio de saturación de base. Es un suelo moderadamente profundo, con penetración efectiva 
de raíces hasta alrededor de 1 metro. Capacidad de uso: clase VI ${ }^{12}$.

Este experimento se realizó en el periodo de marzo a junio sobre una pastura bien establecida de pasto estrella, con aproximadamente 15 años de implantada, la cual nunca fue fertilizada.

El diseño experimental utilizado fue el de bloques completos al azar, con 3 tratamientos de fertilización nitrogenada $(\mathrm{T} 0=$ testigo, $\mathrm{T} 1=40,5 \mathrm{~kg}$ de $\mathrm{N} / \mathrm{ha}, \mathrm{T} 2=81$ $\mathrm{kg}$ de $\mathrm{N} / \mathrm{ha}$ ), con 3 repeticiones cada uno. Como fuente de nitrógeno se utilizó urea granulada, la cual se aplicó en una sola vez al voleo, luego del corte de emparejamiento. El tamaño de la parcela fue de $100 \mathrm{~m}$ de largo por $20 \mathrm{~m}$ de ancho, totalizando una superficie de 18.000 $\mathrm{m}^{2}$ para el ensayo, respetando los límites del piquete.

El día cero del ensayo se realizó un corte de emparejamiento (14/03) a toda la parcela (punto cero de vegetación) y luego la fertilización en sus distintas dosis. Los cortes de muestreo de la pastura se efectuaron los días 23/04, 14/05 y 16/06.

Los sitios de muestreos fueron establecidos eliminando los bordes de las parcelas ( $5 \mathrm{~m}$ de cada lado), cosechándose en la parte central, arrojando al azar un cuadrado de $50 \times 50 \mathrm{~cm}$ y cortando a $10 \mathrm{~cm}$ de altura. El material obtenido se colocó en bolsas y se llevó al laboratorio (Cátedra de Química Analítica y Agrícola, Facultad de Ciencias Agrarias, UNNE), para realizar los respectivos análisis químicos.

El material verde cortado se llevó a estufa a una temperatura de $65^{\circ} \mathrm{C}$ hasta su estabilización, para determinar MS, y posterior molido hasta pasar por malla de $1 \mathrm{~mm}$. El rendimiento de cada corte se expresó en $\mathrm{kg}$ de $\mathrm{MS} / \mathrm{ha}$.

Del material seco y molido se determinaron los distintos componentes nutricionales, siguiendo las determinaciones que se detallan a continuación: contenido de PB por técnica Kjeldahl ( $\mathrm{N}$ total x 6,25) ${ }^{1}$ y fibra detergente neutro (FDN) según la técnica de Van Soest ${ }^{8}$.

Los resultados obtenidos se analizaron estadísticamente mediante análisis de la varianza, empleando el test de Duncan con un nivel de significancia del 5\% para comparar las diferencias entre medias ${ }^{13}$.

\section{RESULTADOS Y DISCUSIÓN}

La producción de MS/ha según los diferentes niveles de fertilización se puede observar en la Figura 1, con mayor producción de MS en el tratamiento T2, cuyo valor alcanzó los $4.339 \mathrm{~kg}$ de MS para el primer corte realizado en el mes de abril, donde la diferencia de producción fue mayor en un $26 \%$ con respecto al tratamientos testigo $(\mathrm{p}<0,05)$, que tuvo una producción de $3.432 \mathrm{~kg}$ de MS/ha. El T1 produjo $4.111 \mathrm{~kg}$ de MS/ha y fue un $20 \%$ mayor que el T0.

En los bloques fertilizados se observó un incremento en la producción de MS a medida que aumentó la dosis de nitrógeno, aunque no se evidenciaron diferencias significativas entre estos tratamientos.
Tabla 1. Promedio de producción de materia seca/hectárea (MS) por corte y total, considerando todos los cortes del ensayo.

\begin{tabular}{ccc}
\hline tratamiento & MS p/corte $(\mathrm{kg})$ & MS total $(\mathrm{kg})$ \\
\hline $\mathrm{T} 0$ & $1,826 \mathrm{a}$ & 5.477 \\
$\mathrm{~T} 1$ & $2,355 \mathrm{ab}$ & 7.065 \\
$\mathrm{~T} 2$ & $2,582 \mathrm{~b}$ & 7.747 \\
\hline
\end{tabular}

Medias con letras distintas difieren estadísticamente $(\mathrm{p}<0,05)$.

Evaluando la producción de MS para todo el período (Tabla 1), se puede observar que a medida que aumentó la cantidad de fertilizante aplicada, aumentó la producción de MS, aunque con diferencias estadísticas solo entre T2 y T0. El mismo comportamiento fue observado en un experimento con pasto Siam, que mostró diferencias estadísticas en producción de MS a partir de los $75 \mathrm{~kg}$ de N/ha ${ }^{4}$.

En otro ensayo, fertilizando pasto estrella con diferentes fuentes de $\mathrm{N}$ y con aplicaciones de $60 \mathrm{~kg} / \mathrm{ha}$, los autores observaron rendimientos estadísticamente superiores al testigo no fertilizado, alcanzando una producción de $4.500 \mathrm{~kg}$ MS/año. El tratamiento de mayor capacidad productiva, presentó una eficiencia de conversión fertilizante a MS de 17,51 kg MS/ha/año por cada kg de nitrógeno aplicado ${ }^{17}$.

La mayor respuesta a la fertilización en los tratamientos realizados en este ensayo, se puede observar en la evaluación de la producción de MS que se produjo en la primera fecha de corte (Figura 1), realizada a principios de otoño, debido a las condiciones de humedad y temperatura ocurridas en ese periodo, que fueron favorables para el crecimiento y desarrollo de la planta, así como las características del fertilizante utilizado, que por tener rápida disponibilidad, permitió que la planta pudiera aprovechar el nutriente en el corto plazo.

A medida que transcurrió el tiempo fue disminuyendo la disponibilidad de humedad del suelo y la temperatura del ambiente, determinando una disminución de la producción de MS en los cortes realizados luego de mediados de otoño. En una experiencia realizada

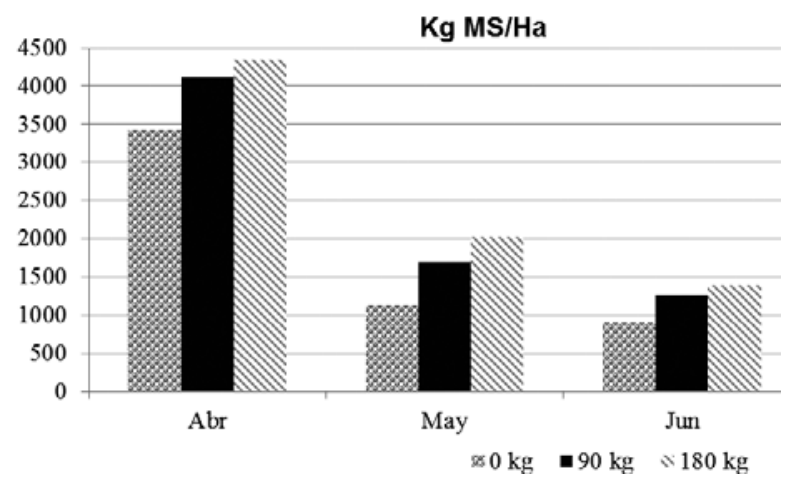

Figura 1. Promedios de producción de materia seca ( $\mathrm{kg} \mathrm{MS} / \mathrm{ha})$, según fecha de corte y tratamiento (0-90$180 \mathrm{~kg}$ de urea/ha). 
Tabla 2. Promedios de concentración de proteína bruta $(\mathrm{PB})$ considerando todos los cortes del ensayo.

\begin{tabular}{ccc}
\hline tratamiento & PB $(\%)$ & media \\
\hline T0 & 6,39 & $\mathrm{a}$ \\
T1 & 7,92 & $\mathrm{~b}$ \\
T2 & 7,24 & $\mathrm{a} \mathrm{b}$ \\
\hline
\end{tabular}

Medias con letras distintas difieren estadísticamente $(\mathrm{p}<0.05)$
Tabla 3. Producción de materia seca (MS) en el primer corte, consumo animal/día (CA) estimado para un novillo de $300 \mathrm{~kg}$ de peso vivo.

\begin{tabular}{cccc}
\hline fertilización & MS $(\mathrm{kg})$ & $\mathrm{CA}(\mathrm{kg})$ & raciones \\
\hline 0 & 3432 & 4,83 & 710 \\
90 & 4111 & 4,99 & 824 \\
180 & 4339 & 5,02 & 864 \\
\hline
\end{tabular}

Cantidad de raciones considerando el consumo de acuerdo al nivel de fertilización utilizado. con pasto Pangola (Digitaria eriantha) y Brachiaria (Brachiaria decumbens), los investigadores concluyeron que el nutriente que limitó en mayor medida el crecimiento de estas pasturas fue el nitrógeno ${ }^{5}$.

La concentración de PB fue afectada por la fertilización nitrogenada (Tabla 2), mostrando un comportamiento similar a la MS, con mayor concentración en $\mathrm{T} 1$, diferente estadísticamente de T0 pero similar a T2. Estos resultados coinciden con los observados en un trabajo con cultivares del género Cynodon, que obtuvieron diferencias significativas de concentración de $\mathrm{PB}$ con distintos niveles de fertilización ${ }^{6}$.

En las pasturas megatérmicas suele ocurrir el efecto "dilución" de la proteína, que consiste en el mantenimiento de la concentración de la PB pero con aumento de la producción total de proteína por hectárea, debido al aumento de la producción de MS. Esto fue explicado por otros autores, quienes detectaron la existencia de una correlación negativa entre el incremento del rendimiento de un pasto y el contenido de proteína ${ }^{11}$. Los autores generaron además ecuaciones para determinar las concentraciones críticas de $\mathrm{N}$ en diversos cultivos $\mathrm{y}$ con ello conocer el estado nutricional de la planta.

En la Figura 2 se puede observar que en la primer fecha de corte existió un efecto directo de la fertilización nitrogenada sobre el contenido de PB: el T1 con un valor de $10,6 \%$, comparado con el T0 que tuvo un valor del $8,8 \%$, con diferencias significativas en esa fecha de corte. El tratamiento T2 con un valor de 9,6\% $\mathrm{PB}$, no presentó diferencias significativas con T1 ni con T0. Los cambios entre los mismos se pueden explicar

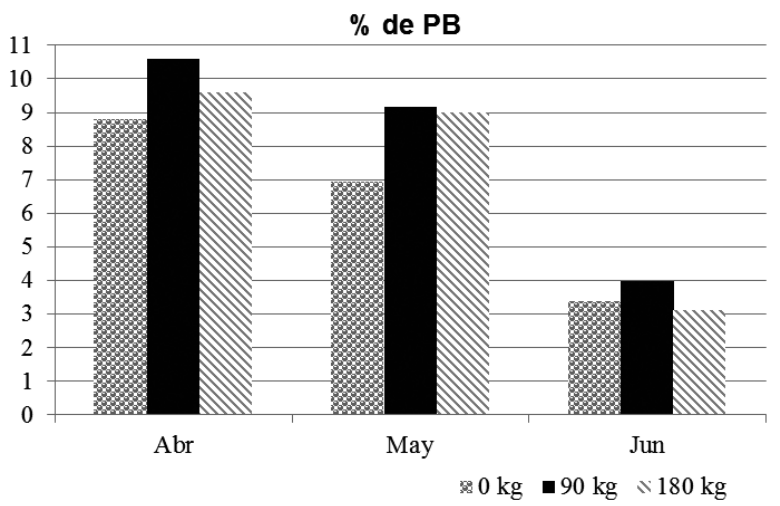

Figura 2. Promedios de concentración de proteína bruta (PB) según fecha de corte y tratamiento $(\mathrm{kg}$ de urea/ha). porque al tener una mayor producción de MS, en T2 se produce una dilución de la proteína, con menor concentración pero mayor producción de $\mathrm{kg}$ de PB total/ha, como se expresó anteriormente. Similares resultados se encontraron trabajando con pasto Siam (Brachiaria mutica) fertilizada con 75, 150 y $225 \mathrm{~kg}$ de N/ha ${ }^{4}$.

El porcentaje de $\mathrm{PB}$ de los diferentes tratamientos disminuyó con la fecha de corte, a medida que avanzó el otoño, al declinar la temperatura ambiente. Similares efectos se constataron en trabajos de fertilización nitrogenada en pasto clavel $^{3}$. El pasto estrella presenta buenos valores de proteína bruta y digestibilidad si es cortado a edades tempranas (30-42 días) y si se le aplican altas dosis de fertilizante $(+400 \mathrm{~kg} / \mathrm{ha} / \mathrm{año})$. En cuanto a la disminución que sufre su calidad con la edad, se comporta como la mayoría de las especies de gramíneas tropicales ${ }^{7}$.

En la Figura 3 se puede observar el efecto de la fertilización nitrogenada sobre la concentración de FDN en las diferentes fechas de corte. Los valores obtenidos en tales ocasiones no presentaron diferencias significativas. Al tener una mayor producción de MS en los tratamientos con fertilizante T1 y T2 pero sin modificarse la concentración de FDN, no se produce disminución de la calidad de la pastura.

La concentración de fibra detergente neutra aumenta al acercarse el invierno disminuyendo la calidad del forraje, y los siguientes cortes arrojan valores de FDN crecientes comparados con el primer corte, pero sin diferencias significativas entre los mismos. Los promedios de concentración de FDN -considerando todos los

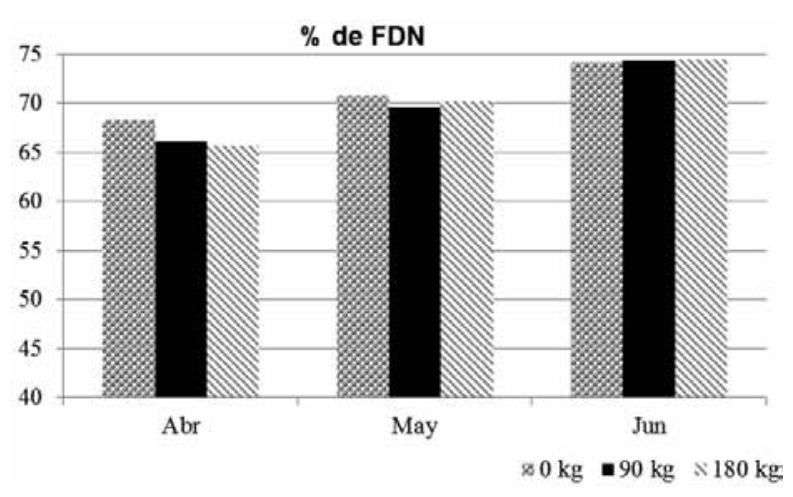

Figura 3. Promedios de concentración de fibra detergente neutro (FDN), según fecha de corte y tratamiento (kg de urea/ha). 
cortes del ensayo- muestran que sus niveles no fueron afectados por la fertilización nitrogenada, con valores entre 70 y $71 \%$.

Estos resultados son similares a los obtenidos en pasto siam ${ }^{4}$, donde la fertilización no afectó la fibra, siendo influida su concentración por la frecuencia de corte. Esto se explica por la fisiología de la planta, que a medida que aumenta su edad se produce su madurez, con incremento de las fracciones estructurales.

Los resultados observados pueden atribuirse a que al aumentar la disponibilidad de $\mathrm{N}$ para el crecimiento de las plantas, coincidiendo con suficiente temperatura y precipitaciones, se genera un aumento de la proporción de hojas, que se manifiesta por la elevación de la concentración de PB y menor FDN en el primer corte.

La calidad de una pastura está determinada por su composición química, digestibilidad y consumo voluntario. El consumo está directamente relacionado con la disponibilidad de forraje y la proporción de fibra de la pastura. A partir de la composición en FDN podemos estimar el consumo potencial de los bovinos, que de acuerdo a los resultados presentados, no sería diferente entre los tratamientos aplicados, aunque sí entre las diferentes fechas de corte, pues en el primer corte se observó mayor proporción de PB y menor de FDN, además de mayor producción de MS.

La mayor cantidad de MS y PB producidas por hectárea, sumadas al mantenimiento de la digestibilidad, significan un aumento de la oferta de MS digestible que implica que se podrá alimentar a un mayor número de animales, mejorando la productividad/ha, impactando directamente sobre el resultado económico del sistema.

Esta respuesta inicial a la fertilización (disponibilidad de $\mathrm{N}$ sumado a temperatura y precipitaciones del período), permite inferir que esta estrategia se podría utilizar para aumentar la disponibilidad de forraje y así diferir la producción de otoño, para que sea pastoreado en el invierno.

Teniendo en cuenta la fórmula para calcular el consumo de bovinos a partir del FDN, a saber: consumo $(\mathrm{kg} \mathrm{MS} / \mathrm{dí} a)=\mathrm{PV} * 1,1 / \% \mathrm{FDN}$ y utilizando los datos obtenidos en este trabajo en cuanto a la producción de MS al primer corte, es dable deducir que se podría aumentar la cantidad de animales en pastoreo debido a la fertilización propuesta (Tabla 3).

En base a los resultados obtenidos se puede concluir que la fertilización nitrogenada del pasto estrella incrementó la producción de MS, de hasta el $40 \%$ para todo el período analizado. La concentración de PB aumentó aproximadamente un $20 \%$ con la aplicación de nitrógeno al inicio del otoño, manteniendo este efecto durante dos meses, luego de lo cual el mismo desaparece.

También surge que la concentración de FDN no es afectada por la fertilización nitrogenada. La combinación de mayor concentración de PB y menor de FDN, significa una mejoría en la calidad nutricional de la pastura en el período inicial post-fertilización.
Agradecimientos. Al Ing.Agr. Juan Pablo Goujon por la disposición y colaboración en el ensayo. A la Empresa Goujon Hnos. por el aporte del predio, maquinaria e insumos que hicieron posible la realización de este trabajo.

\section{REFERENCIAS}

1. Bateman JV. 1970. Nutrición Animal. Manual de métodos analíticos, 1ra ed., Herrero Hermanos, México, 468 p.

2. Burgos JJ. 2011. Las heladas en la Argentina, 2da. ed., Ed. Orientación Gráfica, Buenos Aires, 387 p. ISBN 978-9879260-90-6.

3. Bernardis A et al. 2001. Respuesta de la fertilización nitrogenada en la producción de forraje y proteína cruda de Hermanthria altísima en distintas fechas de crecimiento. XXI Congreso Argentino Producción Animal, Rafaela Santa Fe, Argentina. http://www.revistacyt.unne.edu.ar/ unne/Web/cyt/cyt/2001/5-Agrarias/A-062.pdf

4. Camacho MB. 2011. Productividad, composición química y digestibilidad de Brachiaria mutica ecotipo Siam en respuesta al corte y la fertilización nitrogenada. Tesis de Maestría en Producción Animal Subtropical, FCV, UNNE, $78 \mathrm{p}$.

5. Cameron AG, Ross BJ. 1996. Fertilizer responses of established grass pastures in the Northern Territory (Darwin, Australia). Trop Grasslands 30: 426-429.

6. Cecato U, Santos GT, Assis MD. 2001. Avaliação de cultivares do gênero Cynodon com e sem nitrogênio. Acta Scientiarum 23: 781-788.

7. Finkeros (Finkeros.com: el portal de las fincas). 2013. Pasto estrella Africana. Disponible en http://abc.finkeros. com/pasto-estrella-africana.

8. Goering HK, Van Soest PJ. 1970. Forage fibre analysis: apparatus, reagents, procedures and some applications. Agric Handbook, Agric.Res.Service, Washington DC, 379 p.

9. Jones RM, Evans TR. 1989. Live weight gain from four nitrogen fertilized grasses grazed over the growing season in coastal South-East Queensland (Australia). Tropical Grasslands 23: 75-79.

10. Jones RJ, Jones RM. 1989. Live weight gain from rotationally and continuously grazed pastures of Narok setaria and Samford rhodes grass fertilized with nitrogen in southeast Queensland. Tropical Grasslands 23: 135-142

11. Juárez HJ, Bolaños ED. 2007. Las curvas de dilución de la proteína como alternativa para la evaluación de pastos tropicales. Universidad \& Ciencia 23: 81-90. Disponible en www.ujat.mx/publicaciones/uciencia

12. Ledesma LL, Zurita JJ. 1989. Los suelos del departamento Sargento Cabral, Provincia del Chaco. Carta de Suelos de la República Argentina. Disponible en https:// inta.gob.ar/sites/default/files/script-tmp-inta_informe_ mapa_de_suelo

13. Littel RC. 1989. Statistical analysis of experiments with repeated measurements. Hort Sciences 24: 37-40.

14. National Research Council (NRC). 1996. Nutriment requeriments of beef cattle. Seventh Revised Edition, Nacional Academy Press (Washington, USA), 242 p. 
15. Prause J. 1981. El cultivo del Cynodon Plectostachyus (k.Shum) Pilger (pasto estrella). Control de la erosión del suelo y su posibilidad como forrajera. Boletín del Instituto de Ecología, Recursos Naturales y Tecnología, Ministerio de Economía, Chaco, Argentina, 21 p.
16. Robles SR. 1975. Producción de granos y forrajes, Ed. Limusa, México, $592 \mathrm{p}$.

17. Toll VJ, Martín G, Nicosia M. 2011. Pasto estrella en suelos salinos del NOA. Producir XXI 19: 40-44. Disponible en $w$ ww.produccion-animal.com.ar

\section{SJR sclmaso Journal \& Country Rank}

\section{Powered by}

\section{Revista Veterinaria mantiene su índice de impacto}

Noticias de Scimago Research Group (Scimago Journals \& Country Ranks, Scopus-Elsevier) comunican que la publicación de nuestra casa, Revista Veterinaria, aumentó su índice de impacto. El índice SJR mide la influencia científica (impacto) del artículo de una revista, expresando cuán importante es el "artículo promedio" de la publicación en la discusión científica global (sistema Thomson Reuters).

Para nuestra revista, tal indicador había sido de 0,03 entre 2008 y 2011, aumentando a 0,05 en 2012, a 0,11 en 2013, a 0,108 en 2015 y a 0,100 en 2017, último período evaluado. Asimismo, surge para nuestra publicación un sostenido descenso del indicador que relaciona "citas versus autocitas", demostrando que los autores de los artículos están abandonando la práctica de citar sus propias publicaciones anteriores.

Por último, se advierte que según este portal, nuestra "Revista Veterinaria" continúa siendo la única publicación de esta rama de la ciencia que posee índice de impacto en Argentina. Para el resto del cono sur tal distinción recae en Brasil, Chile, Colombia y Venezuela. En revistas de veterinaria, a nivel mundial el mayor índice de impacto (2,45 puntos) recae en Annual Review of Animal Biosciences (Estados Unidos). 